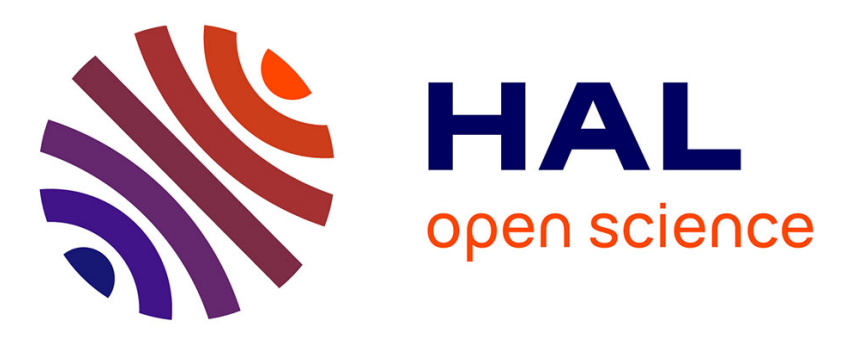

\title{
Benchmark study of TRIPOLI-4 through experiment and MCNP codes
}

Maugan Michel, Romain Coulon, Stéphane Normand, Nicolas Huot, Odile

Petit

\section{- To cite this version:}

Maugan Michel, Romain Coulon, Stéphane Normand, Nicolas Huot, Odile Petit. Benchmark study of TRIPOLI-4 through experiment and MCNP codes. ANIMMA 2011 - Advancements in Nuclear Instrumentation Measurement Methods and their Applications, Centre d'etude de l'energie nucleaire (Belgium); France: Commissariat à l'energie atomique.; Universite de Provence; IEEE Nuclear and Plasma Sciences Society, Jun 2011, Gand, Belgium. 10.1109/ANIMMA.2011.6172891 cea-02500115

\section{HAL Id: cea-02500115 https://hal-cea.archives-ouvertes.fr/cea-02500115}

Submitted on 5 Mar 2020

HAL is a multi-disciplinary open access archive for the deposit and dissemination of scientific research documents, whether they are published or not. The documents may come from teaching and research institutions in France or abroad, or from public or private research centers.
L'archive ouverte pluridisciplinaire $\mathbf{H A L}$, est destinée au dépôt et à la diffusion de documents scientifiques de niveau recherche, publiés ou non, émanant des établissements d'enseignement et de recherche français ou étrangers, des laboratoires publics ou privés. 


\title{
Benchmark Study of TRIPOLI-4 Through Experiment and MCNP Codes
}

\author{
Maugan Michel, Romain Coulon, Stéphane Normand, Nicolas Huot and Odile Petit.
}

\begin{abstract}
Reliability on simulation results is essential in nuclear physics. Although MCNP5 and MCNPX are the world widely used 3D Monte Carlo radiation transport codes, alternative Monte Carlo simulation tools exist to simulate neutral and charged particles' interactions with matter. Therefore, benchmark are required in order to validate these simulation codes. For instance, TRIPOLI-4.7, developed at the French Alternative Energies and Atomic Energy Commission for neutron and photon transport, now also provides the user with a full feature electron-photon electromagnetic shower. Whereas the reliability of TRIPOLI-4.7 for neutron and photon transport has been validated yet, the new development regarding electron-photon matter interaction needs additional validation benchmarks. We will thus demonstrate how accurately TRIPOLI-4's "deposited spectrum" tally can simulate gamma spectrometry problems, compared to MCNP's "F8" tally. The experimental setup is based on an HPGe detector measuring the decay spectrum of an ${ }^{152} \mathrm{Eu}$ source. These results are then compared with those given by MCNPX 2.6d and TRIPOLI-4 codes.

This paper deals with both the experimental aspect and simulation. We will demonstrate that TRIPOLI-4 is a potential alternative to both MCNPX and MCNP5 for gamma-electron interaction simulation.
\end{abstract}

Index Terms-TRIPOLI, MCNP5, MCNPX, Benchmark, Monte Carlo simulation, Gamma-ray spectrometry, HPGe, Efficiency calibration

\section{INTRODUCTION}

W ITH the growing need for simulation in nuclear research and industry [1], reliable results given by Monte-Carlo codes is important for economic requirements. Continuously developped since the 1970's and available from the OECD/NEA databank since 2003, TRIPOLI-4 [2] (TRIdimensional POLYkinetic) is a 3D continuous-energy MonteCarlo transport code. It is the reference Monte-Carlo neutron transport code for France and its efficiency to meet the requirements in core criticity simulation or radiation protection studies has been reviewed by many publications [3], [4], [5]. Both TRIPOLI-4 and MCNPX [6] have been extensively benchmarked regarding neutrons' transport, but the "deposited

Corresponding author. Tel: +33 116908 25 27, E-mail address: maugan.michel@cea.fr (M. Michel)

Manuscript received May 23, 2011.

M. Michel is with CEA, LIST, Laboratoire Capteurs et Architectures Électroniques, F-91191 Gif-sur-Yvette, France .

R. Coulon was with the CEA, LIST, Laboratoire Capteurs et Architectures Électroniques, F-91191 Gif-sur-Yvette, France. He is now with Canberra France, F-78182 Saint Quentin en Yvelines, France. E-mail: romain.coulon@canberra.com

S. Normand is with the CEA, LIST, Laboratoire Capteurs et Architectures Électroniques, F-91191 Gif-sur-Yvette, France. E-mail: stephane.normand@cea.fr

N. Huot is with the CEA, DANS, SERMA, F-91191 Gif-sur-Yvette, France.

O. Petit is with the CEA, DANS, SERMA, F-91191 Gif-sur-Yvette, France. spectrum" capability offered by TRIPOLI-4, equivalent to MCNP's "F8" tally still has to be reviewed. The main purpose of this paper, in which we will compare simulations and experiment, is to provide a benchmark for TRIPOLI-4 and to show that this code's full feature electron-photon electromagnetic shower is a good alternative to both world reference codes in the latest versions we could use: MCNPX 2.6d and MCNP5 [7].

For this benchmark, we will rely on three different models that have been studied in the past years.

The first study was able to complete a partial benchmark of TRIPOLI-4.6 through MCNP5. It is re-run in order to observe the behaviour of TRIPOLI-4.7 and MCNPX as well. The second study completes the first by adding complexity to the geometry. The last study, in which simulations are compared to experimental results shows as well the importance of the knowledge of the geometry when dealing with nuclear instrumentation simulation.

The three studies are reviewed one by one, the description of their setup and the results they yielded being analyzed qualitatively and/or quantitatively.

\section{STUdies' OVERVIEW}

During this benchmark, we used TRIPOLI-4 (version 4.7) and MCNPX (version 2.6d), unless stated otherwise.

Each study concerns the measurement of an ${ }^{152} \mathrm{Eu}$ source which's discrete gamma ray spectrum was taken from JANIS (ENDF/B-VII.0 database [8]). MCNPX's "F8" tally is used to determine the deposited energy in the germanium detectors while TRIPOLI-4's analogous function, the "deposited spectrum" response is used. Both are defined with $1 \mathrm{keV}$ bins and considering a punctual radioactive source.

To subtract the Compton contribution from the different peaks at a given energy $(N(E)$ denotes the number of full absorbed photons of energy $E$, centered on bin $n$ ), obtained from equation (1):

$$
N(E)=N_{n}-\frac{N_{j}}{6}\left(j \in\{n-3, \cdots, n+3\} \backslash n ; n \in \mathbb{N}^{*}\right)
$$

The relative error $\varepsilon$ on the intensity $N_{i}$ of the $i$ th photopeak of each simulation, relatively to a reference (be it MCNP5, MCNPX or experimental data), is calculated using:

$$
\varepsilon_{i}=\frac{N_{i}-N_{\operatorname{Ref}_{i}}}{N_{\operatorname{Ref}_{i}}}
$$




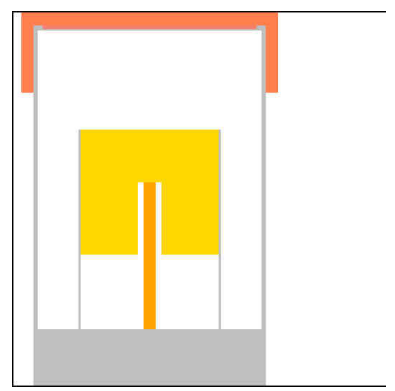

Fig. 1. First study. Simulated geometry (TRIPOLI-4 screenshot).

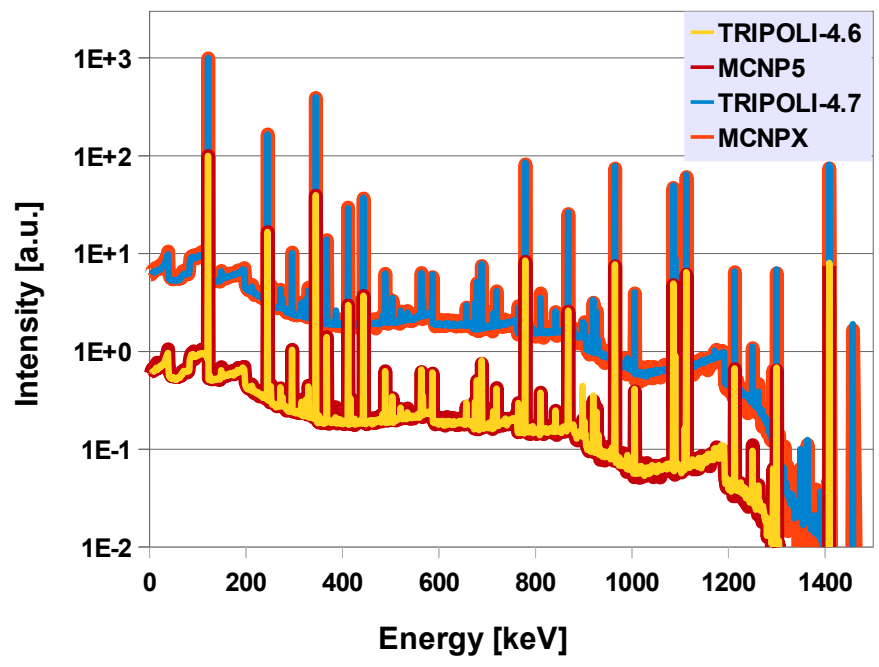

Fig. 2. First study. Simulated spectra.

Most intense: TRIPOLI-4.7 (thin) and MCNPX (thick).

Least intense: TRIPOLI-4.6 (thin) and MCNP5 (thick).

The difference in intensity between simulated spectra is for visualization purpose only.

and its relative uncertainty [9], $\frac{\sigma_{\varepsilon_{i}}}{N_{i}}$ :

$$
\begin{gathered}
\frac{\sigma_{\varepsilon_{i}}}{\varepsilon_{i}}=\sqrt{\left(\frac{\sigma_{N_{i}}}{N_{i}}\right)^{2}+\left(\frac{\left.\sigma_{N_{\mathrm{Ref}_{i}}}\right)_{\operatorname{Ref}_{i}}}{2}\right.} \\
\Delta \varepsilon_{\operatorname{sim}_{i}}^{2}=\left(\frac{\partial \varepsilon_{\operatorname{sim}_{i}}}{\partial N_{\operatorname{sim}_{i}}}\right)^{2} \cdot \sigma_{\operatorname{sim}_{i}}^{2}+\left(\frac{\partial \varepsilon_{\operatorname{sim}_{i}}}{\partial N_{\operatorname{Ref}_{i}}}\right)^{2} \cdot \sigma_{N_{\mathrm{REF}_{i}}^{2}}
\end{gathered}
$$

\section{A. First Study}

Conducted two years ago within the frame of the work of R. Coulon [10], [11], a posteriori missing information concerning the surroundings of the experiment impeached the feasibility of a complete benchmark. The results produced by this study can although be used for a comparison of the only codes. Simulated geometry is presented in Fig. 1.

As can be seen in Fig. 2, both TRIPOLI-4.6 and TRIPOLI4.7, yield qualitatively identical results to those of MCNP5 and MCNPX's. Quantitative results are presented in Fig. 3 and reported in Table I.

Although the mean bias is less than $4 \%$ (see Table I), which is considered as good in many studies, it can be assumed that TRIPOLI-4 could be considered as a good candidate for these studies.

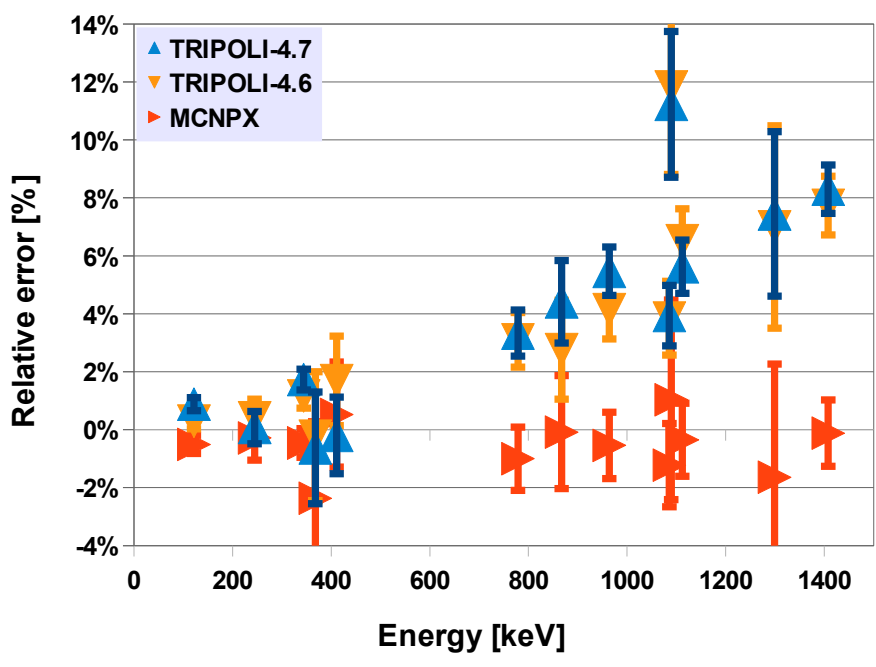

Fig. 3. First study. Relative error of TRIPOLI-4.6, TRIPOLI-4.7 and MCNPX simulated photopeaks of the ${ }^{152} \mathrm{Eu}$ source simulated; MCNP5 is used as reference.

TABLE I

First STUdy. PEAK RELATIVE ERROR TO MCNP5 FOR EACH CODE

\begin{tabular}{cccc}
\hline $\begin{array}{c}\text { Energy } \\
(\mathbf{k e V})\end{array}$ & $\begin{array}{c}\text { TRIPOLI-4.6 } \\
(\boldsymbol{\%})\end{array}$ & $\begin{array}{c}\text { TRIPOLI-4.7 } \\
(\boldsymbol{\%})\end{array}$ & $\begin{array}{c}\text { MCNPX } \\
(\boldsymbol{\%})\end{array}$ \\
\hline 121.8 & $0.29 \pm 0.26$ & $0.88 \pm 0.23$ & $-0.51 \pm 0.31$ \\
244.7 & $0.41 \pm 0.65$ & $0.08 \pm 0.56$ & $-0.29 \pm 0.76$ \\
344.3 & $1.16 \pm 0.42$ & $1.73 \pm 0.36$ & $-0.46 \pm 0.49$ \\
367.8 & $-0.22 \pm 2.22$ & $-0.63 \pm 1.92$ & $-2.36 \pm 2.64$ \\
411.1 & $1.69 \pm 1.54$ & $-0.20 \pm 1.32$ & $0.52 \pm 1.81$ \\
778.9 & $3.10 \pm 0.94$ & $3.34 \pm 0.79$ & $-1.00 \pm 1.09$ \\
867.4 & $2.76 \pm 1.70$ & $4.41 \pm 1.42$ & $-0.09 \pm 1.95$ \\
964.1 & $4.14 \pm 1.01$ & $5.47 \pm 0.84$ & $-0.54 \pm 1.15$ \\
1085.8 & $3.85 \pm 1.27$ & $3.94 \pm 1.04$ & $-1.22 \pm 1.44$ \\
1089.7 & $11.82 \pm 3.02$ & $11.23 \pm 2.51$ & $1.03 \pm 3.44$ \\
1112.1 & $6.52 \pm 1.10$ & $5.63 \pm 0.92$ & $-0.35 \pm 1.26$ \\
1299.1 & $7.00 \pm 3.49$ & $7.44 \pm 2.84$ & $-1.64 \pm 3.90$ \\
1408.0 & $7.73 \pm 1.01$ & $8.30 \pm 0.84$ & $-0.12 \pm 1.15$ \\
Mean & $3.87 \pm 1.43$ & $3.97 \pm 1.20$ & $-0.54 \pm 1.65$ \\
\hline
\end{tabular}

The first geometry was rather simple concerning photon scattering in the surroundings of the source, a more complex simulation was decided and conducted during this work.

\section{B. Second Study}

In order to compare the difference between TRIPOLI-4 and MCNPX in a more complex situation, another study was started, inspired by the measurement of an ${ }^{152} \mathrm{Eu}$ source inside a lead shield.

The shield used as a basis for this work is model 667 from Canberra, with copper, tin and lead layers (see Fig. 4)

Fig. 5 shows that TRIPOLI-4's relative error to MCNPX increases with energy, from $3.82 \%(244 \mathrm{keV})$ to $20.47 \%$ $(1299 \mathrm{keV})$, with a mean uncertainty of $1.63 \%$.

While MCNP codes simulate a given number of particles' histories (NPS), TRIPOLI- 4 simulates $B$ batches of $N$ particles, yielding, when NPS $=B \times N$, simulations with similar uncertainty. The increase in relative error of TRIPOLI- 4 , in 


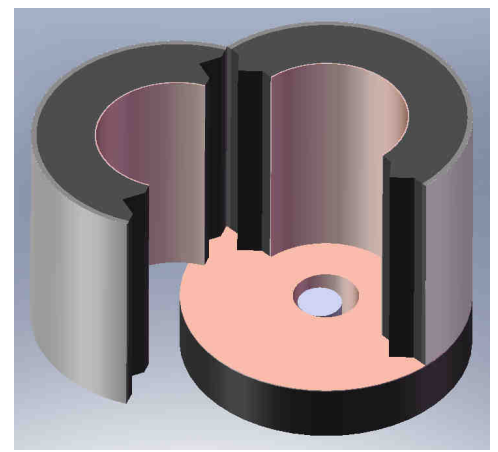

(a) 3D view of the lead shield and the HPGe detector.

Fig. 4. Second study. Lead shield and sensor views.

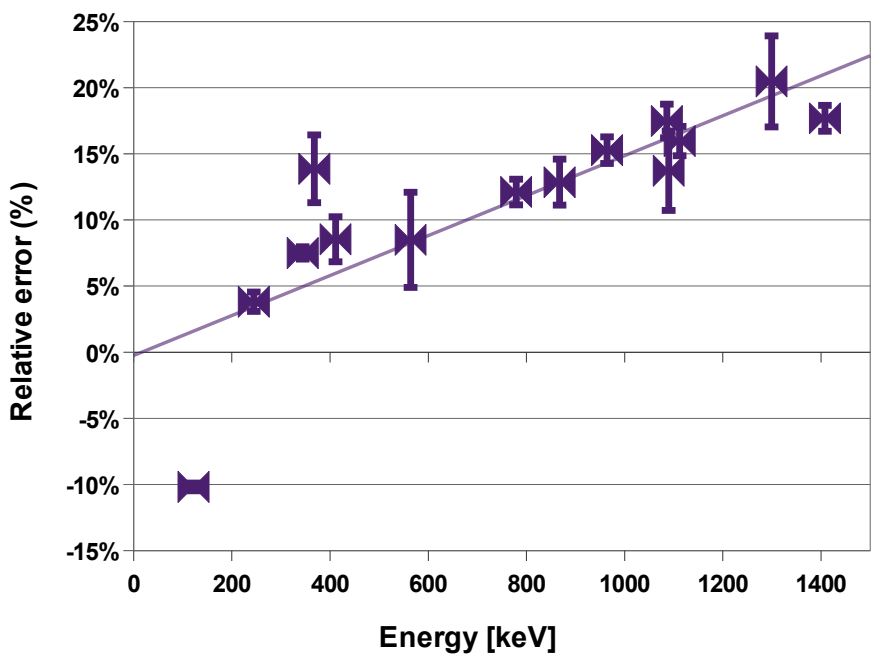

Fig. 5. Second study. Relative error of TRIPOLI-4, compared to MCNPX.

this study, is currently investigated.

\section{Third Study}

The last study aims at comparing both codes with the experimental calibration curve of an HPGe diode, measured and calculated by a primary radioactive metrology laboratory. MAESTRO (Ortec) and COLEGRAM [12] were used for data acquisition and processing.

The main dimensions of the detector (GMX35P4, Ortec, $35 \%$ relative efficiency) is based on the datasheet, coherent with radiographies (see Fig. 6). Results from MCNPX and TRIPOLI-4 are compared to the detector's calibration curve (Fig. 7), with a correction on simulated photopeaks probability using the JANIS database intensity values $\left(\eta_{i}\right)$ and equation (1):

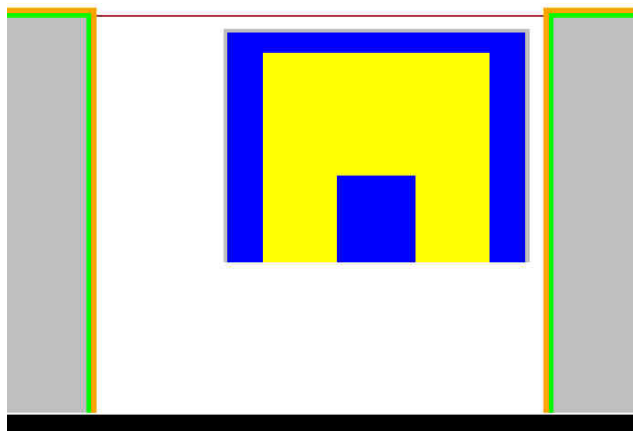

(b) Simulated geometry (TRIPOLI-4 screenshot). Left to right, starting from the hole in the germanium: vacuum, germanium, vacuum, aluminium, copper, tin, lead. Layer above the detector: polyethylene.

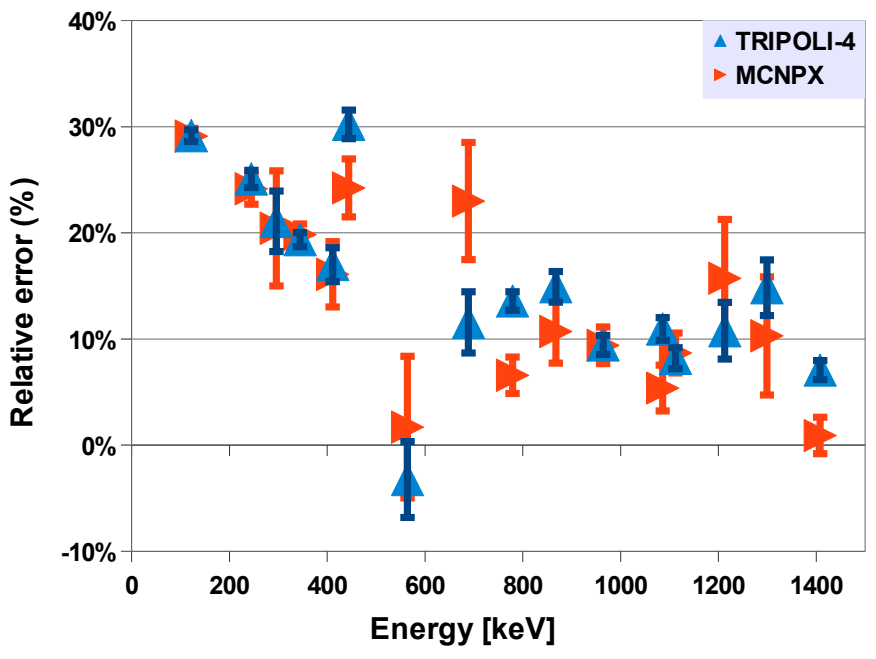

Fig. 7. Third study. Simulations (TRIPOLI-4 and MCNPX) compared to the calibration results of an ${ }^{152} \mathrm{Eu}$ source measured by the REGe GMX35P4 diode.

$$
I_{i}=\frac{N_{i}}{\eta_{\mathrm{JANIS}}}
$$

Results of this comparison are presented in Fig. 7. TRIPOLI-4 is also compared to MCNPX (Fig. 8).

Considering the detector manufacturer's datasheet, the difference between codes and experiment range from $29 \%$ (121 keV) to $1 \%(1408 \mathrm{keV})$ [Table II]. Such disagreement, also observed in other studies may be reduced by optimizing detector parameters [14], [15], [16], [17], [13], [18], and particularly the dead layer [19].

The two large discrepancies on the $444 \mathrm{keV}$ and $564 \mathrm{keV}$ photopeaks are probably due to a too low peak intensity and insufficient number of simulated particles. This problem is currently investigated. 


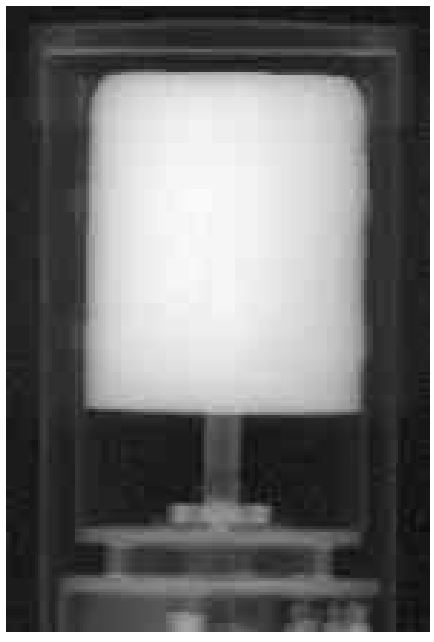

(a) Radiography.

Fig. 6. Third study. REGe GMX35P4 (Ortec, $35 \%$ relative efficiency)

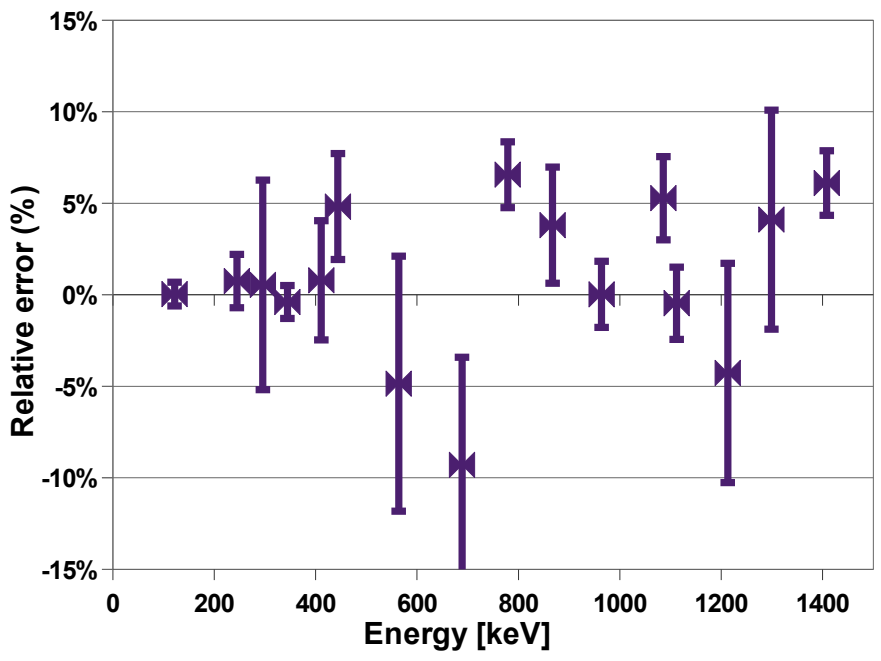

Fig. 8. Third study. TRIPOLI-4 comparison to MCNPX.

\section{CONCLUSION}

From the three studies presented in this article, it can be asserted that, besides neutron transport - for which it has been validated, TRIPOLI- 4 can also be used as a reference for the simulation of gamma instrumentation.

The first study showed that TRIPOLI-4 results differ from those of MCNP5 with a mean relative error of less than $4 \%$. Also, the qualitative results from this study shows that the Compton spectra from TRIPOLI-4.6 and TRIPOLI-4.7 perfectly match those of MCNP5 and MCNPX.

In the second study in which a more complex geometry is simulated, TRIPOLI-4 presnets a mean relative error compared to MCNPX which is, considering results of the first and second study, probably due to an insufficient number of simulated particles.

The last study showed a good agreement between TRIPOLI4 and MCNPX with relative errors to within $10 \%$ and a mean relative error of $0.85 \pm 1.06 \%$ (median value: $0.32 \%$ ). Since MCNPX's "F8" tally is validated by many studies for

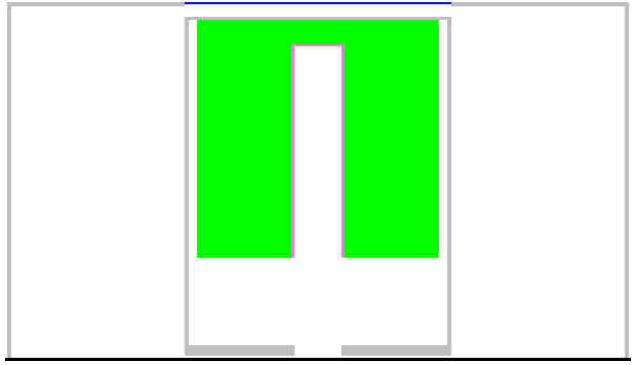

(b) Simulated geometry (TRIPOLI-4 screenshot). In pink: Ge-Li dead layer, not used as a scoring cell.

TABLE II

THIRD STUDY. ${ }^{152}$ Eu PEAKS RELATIVE ERRORS.

\begin{tabular}{|c|c|c|c|c|}
\hline \multirow{2}{*}{$\begin{array}{l}\text { Energy } \\
(\mathrm{keV})\end{array}$} & \multirow{2}{*}{$\begin{array}{c}\text { Intensity } \\
\times 10^{-3}\end{array}$} & \multicolumn{2}{|c|}{ Codes $v s$ experiment } & \multirow{2}{*}{$\begin{array}{c}\text { TRIPOLI-4 } \\
\text { vs MCNPX } \\
(\%)\end{array}$} \\
\hline & & $\begin{array}{c}\text { TRIPOLI-4 } \\
(\%)\end{array}$ & $\begin{array}{c}\text { MCNPX } \\
(\%)\end{array}$ & \\
\hline 121.8 & 179 & $29.15 \pm 0.55$ & $29.10 \pm 0.76$ & $0.04 \pm 0.65$ \\
\hline 244.7 & 48 & $25.08 \pm 0.81$ & $24.15 \pm 1.44$ & $0.75 \pm 1.45$ \\
\hline 295.9 & 3 & $21.08 \pm 2.84$ & $20.43 \pm 5.42$ & $0.54 \pm 5.72$ \\
\hline 344.3 & 167 & $19.37 \pm 0.66$ & $19.84 \pm 0.99$ & $-0.40 \pm 0.90$ \\
\hline 411.1 & 14 & $17.01 \pm 1.59$ & $16.09 \pm 3.08$ & $0.79 \pm 3.26$ \\
\hline 444.0 & 18 & $30.21 \pm 1.34$ & $24.23 \pm 2.73$ & $4.82 \pm 2.89$ \\
\hline 564.0 & 3 & $-3.25 \pm 3.58$ & $1.70 \pm 6.68$ & $-4.86 \pm 6.96$ \\
\hline 688.7 & 5 & $11.56 \pm 2.89$ & $22.99 \pm 5.52$ & $-9.30 \pm 5.88$ \\
\hline 778.9 & 82 & $13.58 \pm 0.87$ & $6.58 \pm 1.72$ & $6.56 \pm 1.80$ \\
\hline 867.4 & 27 & $14.91 \pm 1.45$ & $10.71 \pm 2.98$ & $3.80 \pm 3.17$ \\
\hline 964.1 & 91 & $9.43 \pm 0.89$ & $9.40 \pm 1.72$ & $0.02 \pm 1.81$ \\
\hline 1085.8 & 64 & $10.94 \pm 1.07$ & $5.38 \pm 2.17$ & $5.28 \pm 2.28$ \\
\hline 1112.1 & 84 & $8.18 \pm 0.99$ & $8.68 \pm 1.89$ & $-0.46 \pm 1.97$ \\
\hline 1213.0 & 9 & $10.78 \pm 2.68$ & $15.72 \pm 5.55$ & $-4.27 \pm 6.00$ \\
\hline 1299.1 & 10 & $14.82 \pm 2.62$ & $10.29 \pm 5.56$ & $4.11 \pm 5.98$ \\
\hline 1408.0 & 131 & $7.07 \pm 0.90$ & $0.90 \pm 1.72$ & $6.11 \pm 1.76$ \\
\hline & Mean & $12.66 \pm 1.66$ & $11.73 \pm 3.25$ & $0.94 \pm 3.43$ \\
\hline & Median & 11.56 & 10.29 & 0.79 \\
\hline
\end{tabular}

this problematic, TRIPOLI-4's equivalent, "deposited spectrum" may be considered the same. When compared to the experiment, both codes present a relative error on photopeaks ranging from $29 \%$ to $1 \%(121 \mathrm{keV}$ and $1408 \mathrm{keV})$.

While they can be used when uncertainty isn't critical, Monte Carlo codes cannot be used for metrological purpose since critical parameters (e.g. exact material constitution or geometry) are known with a confidence level significantly low. They are, yet, valid for approximation when setting up the experiment is impossible or difficult [1], [20].

\section{ACKNOWLEDGMENT}

The authors would like to thank CEA/DRT for financial support and Messrs. J. Plagnard and B. Rattoni (CEA/LIST) 
for the experimental data and radiographies.

\section{REFERENCES}

\section{REFERENCES}

[1] D.Karamanis, Efficiency simulation of HPGe and Si(Li) detectors in $\gamma$ and $X$-ray spectroscopy, D. Karamanis, Nuclear Instruments and Methods in Physics Research A, vol. 505, pp 282-285, 2003.

[2] TRIPOLI Project Team, TRIPOLI-4 user guide, Report CEA-R-6169, 2008.

[3] Y.K. Lee, Validation of TRIPOLI-4 Perturbation in Criticality Safety analysis, ICNC 2007, Saint Petersbourg, Russia.

[4] J.C. Trama and others, Overview of TRIPOLI-4.5, ICRS08, Denver, August 2008.

[5] C. Fausser and others, Numerical benchmarks TRIPOLI - MCNP with use of MCAM on FNG ITER bulk shield and preliminary FNG HCLL TBM mock-up, Symposium On Fusion Technology, Porto, 2010.

[6] J.S. Hendrick and others, MCNPX version 26D, Los Alamos National Laboratory Report LA-UR-07-4137, 2007.

[7] R.A. Forster and L.J. Cox and R.F. Barrett and T.E Booth and J.F. Briesmeister and F.B. Brown and J.S. Bull and G.C. Geisler and J.T. Goorley and R.D. Mosteller and others, MCNP Version 5, Nuclear Instruments and Methods in Physics Research B, volume 213, pp 82-86, 2004.

[8] M.B. Chadwick and P. Oblozinsky and M. Herman and N.M. Greene and R.D. McKnight and D.L. Smith and P.G. Young and R.E. MacFarlane and G.M. Hale and S.C. Frankle and others, Nuclear Data Sheets, volume 107, no. 12, pp 2931-3060, 2006.

[9] G.F. Knoll, Radiation detection and measurement, 4th edition, Wiley and Sons, pp 85-92, 2010.

[10] R. Coulon and S. Normand and G. Ban and E. Barat and T. Montagu and T. Dautremer and H.-P. Brau and V. Dumarcher and J.-L. Portier and M. Michel and L. Barbot and T. Domenech and K. Boudergui and V. Kondrasovs and A.-M. Frelin and J.-M. Bourbotte and P. Jousset, Sodium fast reactor power monitoring and clad failure detection using ADONIS system, Nuclear Science Symposium Conference Record (NSS/MIC), pp 1378-1386, 2009.

[11] Michel, M. Benchmark Test of TRIPOLI4 and MCNP5 Codes in Gamma Spectrometry Field, Master's Thesis of Blaise Pascal University, 2009.

[12] M.-C. Lépy, Presentation of the COLEGRAM software, Note Technique LHNB/04/26, 2004.

[13] M. Jurado Vargas and A.L. Guerra, Application of PENELOPE code to the efficiency calibration of coaxial germanium detectors, Applied Radiation and Isotopes, vol. 64, pp 10-11, 2006.

[14] M.-C. Lépy and others, Intercomparison of efficiency transfer software for gamma-ray spectrometry, Applied Radiation and Isotopes, vol. 55, no. 4, 493-503, October 2001.

[15] T. Vidmar and others, An intercomparison of Monte Carlo codes used in gamma-ray spectrometry, Applied Radiation and Isotopes, vol. 66, no. 67, pp. 764-768, 2008.

[16] P. Dryak and P. Kovar, Experimental and MC determination of HPGe detector efficiency in the 40-2754 keV energy range for measuring point source geometry with the source-to-detector distance of $25 \mathrm{~cm}$, Applied Radiation and Isotopes, vol. 64, no. 10-11, pp 1346-1349, 2006.

[17] T. Vidmar and A. Likar, Automated construction of detector models for efficiency interpolation in gamma-ray spectrometry, Applied Radiation and Isotopes, vol. 56, pp 99-103, 2002.

[18] R.M. Keyser and W.K. Hensley, Efficiency of germanium detectors as a function of energy and incident geometry: comparison of measurements and calculations.

[19] J. Ródenas and others, Analysis of the influence of germanium dead layer on detector calibration simulation for environmental radioactive samples using the Monte Carlo method, Nuclear Instruments and Methods in Physics Research A, vo. 496, no. 2-3, pp. 390-399, 2003.

[20] R. Coulon et al, Sodium Fast Reactors power monitoring using high resolution and high count rate gamma spectrometry. Simulation study, IEEE Nuclear Science Symposium Conference Record NSS'08, 2008. 